\title{
Serum paraoxonase activity is decreased in the active stage of Behçet's disease
}

\author{
S Karakucuk, G Baskol, A O Oner, M Baskol, E Mirza, M Ustdal
}

Br J Ophthalmol 2004;88:1256-1258. doi: 10.1136/bjo.2004.043398

\begin{abstract}
Aims: To evaluate paraoxonasel (PON1) activities and malondialdehyde (MDA) levels, one of the end products of lipid peroxidation induced by reactive oxygen species in patients with Behçet's disease (BD) in the active stage.

Methods: Serum MDA levels and PON1 levels were measured spectrophotometrically in 16 patients with $B D$ in the active stage of the disease and in 15 healthy subjects who constituted the control group.

Results: In the BD group, median (range) serum PON1 and MDA levels were 149.64 U/I (88.02-281.68) and $1.21 \mathrm{nmol} / \mathrm{ml}(0.90-3.42)$, respectively. In the control group, median (range) serum PON1 and MDA levels were $206.86 \mathrm{U} / \mathrm{I}(114.43-422.52)$ and $0.72 \mathrm{nmol} / \mathrm{ml}$ (0.50$1.12)$, respectively. There was a statistically significant decrease in serum PON1 levels $(p=0.02)$ and an increase in serum MDA levels $(p<0.001)$ in patients with BD in the active stage when compared to controls.

Conclusion: Endothelial damage and increased polymorph nuclear leucocyte activity in the active stage of $B D$ could result in a pro-oxidation environment which, in turn, results in decreased antioxidant PON activity and increased lipid peroxidation as evidenced by increased MDA levels.
\end{abstract}

B ehçet's disease (BD) is a multisystem disorder that is characterised by ocular and skin manifestations as well as genital and oral ulcers; it is a chronic relapsing inflammatory process and its predominant histopathology is vasculitis with vessel walls and perivascular tissue infiltrated mainly by lymphocytes but also by monocytes, plasma cells, and neutrophils. ${ }^{1}$

The aetiology and pathogenesis of BD have not yet been clarified. Recently, attention has been focused on the role of reactive oxygen species (ROS) produced by activated neutrophils during the inflammatory response. Oxidative stress is reported to be increased in $\mathrm{BD}$, due to overproduction of ROS and decreased efficiency of antioxidant defences. Decreased enzyme activity in the antioxidant system and increased levels of free radicals in patients with $\mathrm{BD}$ may also have a role in tissue damage. . $^{3-5}$

Neutrophil derived oxygen intermediates may contribute to tissue damage, particularly in the endothelial tissue. ${ }^{3}$ These oxygen intermediates also affect lipid and lipoproteins and result in their oxidation yielding oxidation products. Lipids and lipoprotein peroxidation are considered to be important in the pathogenesis of atherosclerosis. ${ }^{6}$ Lipid and lipoprotein profiles and their relation with atherogenesis were described in patients with $\mathrm{BD}^{7-9}$

Serum paraoxonase (PON) is a calcium dependent esterase that is known to catalyse hydrolysis of organophosphates, and is widely distributed among tissues including liver, kidney, intestine. ${ }^{10-12}$
PON, which is exclusively bound to high density lipoprotein (HDL), is recognised as an antioxidant enzyme since it hydrolyses lipid peroxides. ${ }^{12}$ It was reported that HDL associated PON inhibited not only low density lipoprotein oxidation, but also HDL oxidation when induced by different oxidation modes (transition metal ions, free radicals)..$^{13}$

In this study, we aimed to evaluate PONl activities and malondialdehyde (MDA) levels, one of the end products of lipid peroxidation induced by ROS in patients with BD in the active stage of the disease.

\section{PATIENTS AND METHODS}

In this study we measured serum PONl and MDA levels in 16 patients with BD who were followed up by the uvea-Behçet clinic of the ophthalmology department of Erciyes University Medical Faculty, Kayseri, Turkey, and who were in the eye clinic because of uveitis in its active stage. Results are compared with 15 age and sex matched healthy controls. Diagnosis of $\mathrm{BD}$ was made according to the criteria set by the International Study Group for Behçet's Disease which necessitates the presence of oral ulceration plus any two of genital ulceration, typical defined eye lesions, typical defined skin lesions, or a positive pathergy test. ${ }^{14}$ In all patients during the active stage oral, genital, and eye lesions were present and in the majority; skin lesions were also present. Systemic evaluation of the patients and the controls was made by an internal medicine specialist.

All reagents were purchased from Sigma (Sigma-Aldrich Corp, St Louis, MO, USA) and Merck (Merck KgaA, Darmstadt, Germany). Blood samples were obtained after an overnight fast and serum immediately separated. Serum samples were stored at $-70^{\circ} \mathrm{C}$ until analysis.

Serum MDA levels were measured according to a method described elsewhere. ${ }^{15}$ The principle of the method was based on the spectrophotometric measurement of the colour occurring during the reaction of thiobarbituric acid with MDA. Concentration of thiobarbituric acid reactive substances was calculated by the absorbance coefficient of the malondialdehyde-thiobarbituric acid complex and expressed as $\mathrm{nmol} / \mathrm{ml}$. As a standard, MDA bis(dimethyl acethal)-TBA (thiobarbituric acid) complex was used.

One unit of paraoxanase activity is defined as $1 \mu \mathrm{mol}$ of p-nitrophenol formed per minute and activity was expressed as unit per litre of serum (U/l) according to the method described by Eckerson et al. ${ }^{16}$

The study protocol was approved by the ethics committee of Erciyes University and consent was obtained from the subjects before the study. Statistical evaluation was carried out with the SPSS 10.0 (Statistical Packages for Social Sciences; SPSS Inc, Chicago, IL, USA). Data obtained from the study groups were compared by the non-parametric

Abbreviations: $B D$, Behçet's disease; $H D L$, high density lipoprotein; MDA, malondialdehyde; PONI, paraoxonase 1; ROS, reactive oxygen species 
Table 1 Serum PON and MDA levels in patients with BD and controls

\begin{tabular}{lllll}
\hline & $\mathbf{B D}(\mathbf{n}=16)$ & & Control $(\mathbf{n}=15)$ & \\
\cline { 2 - 3 } Factors & Median (range) & Median (range) & P Value \\
\hline PON1 (U/l) & $149.64(88.02-281.68)$ & $206.86(114.43-422.52)$ & $0.02^{*}$ \\
MDA (nmol/ml) & $1.21(0.90-3.42)$ & $0.72(0.50-1.12)$ & $<0.001^{*}$ \\
\hline *Statistically significant difference between patients with BD and controls, Mann-Whitney U test. & \\
\hline
\end{tabular}

Mann-Whitney $\mathrm{U}$ test; a p value less than 0.05 was considered as statistically significant. The results were presented as median values with their range.

\section{RESULTS}

The median age of the 16 patients was 32 (range 2259 years) and that of the control group was 35 (range 1851 years). There was no statistically significant difference in age and sex distribution between the patients and control groups $(p=0.30)$.

In the BD group, median (range) serum PONl and MDA levels were $149.64 \mathrm{U} / \mathrm{l}(88.02-281.68)$, and $1.21 \mathrm{nmol} / \mathrm{ml}$ (0.90-3.42), respectively. In the control group, median (range) serum PONl and MDA levels were $206.86 \mathrm{U} / \mathrm{l}$ (114.43-422.52), and $0.72 \mathrm{nmol} / \mathrm{ml}(0.50-1.12)$, respectively.

Serum PONl and MDA levels are shown on table 1. When compared with healthy controls, there was a statistically significant decrease in serum PONl levels $(\mathrm{p}=0.02)$ and a significant increase in serum MDA levels $(\mathrm{p}<0.001)$.

\section{DISCUSSION}

Neutrophils, lymphocytes, and macrophages release cytokines, growth factors, and ROS upon activation. ${ }^{17}$ An imbalance between the pro- oxidant and antioxidant system may result in formation of excessive ROS; these ROS molecules are highly reactive and capable of attacking almost every cell component, which in turn causes further damage to surrounding tissues. ROS overwhelms the protective systems and results in cell damage and lipid peroxidation. This mechanism has a crucial and probably a causative role in the pathogenesis of various acute and chronic diseases including inflammation, rheumatoid arthritis, and atherosclerosis. ${ }^{18} 19$ There are several reports suggesting that increased ROS production in patients with $\mathrm{BD}$ causes cell and tissue injury. ${ }^{3-5}$

ROS can attack double bonds in polyunsaturated fatty acids, and thus induce lipid peroxidation, which in turn results in further oxidative damage. ${ }^{20} 21$ ROS mediated oxidation of cell membrane lipids leads to the formation of lipid peroxidation products, such as MDA. ${ }^{22}$ Increased plasma MDA levels in patients with BD have been shown in previous studies ${ }^{23}$; we obtained similar results in the present study. When compared with healthy controls, we found a statistically significant increase in serum MDA levels $(p<0.001)$, which is evidence of increased lipid peroxidation during the active stage of the disease.

We found decreased serum PONI activity in BD patients in comparison with healthy controls during the ocular activation stage of the disease. No other studies have been cited in the literature dealing with serum PON activity in BD. The mechanism of the observed decrease in serum PON activity in BD patients is unclear. Serum PONl activity is generally considered to vary in response to the consumption of PONI for the prevention of oxidation. The decrease in serum PON activity in our BD patients might have resulted from the increased inactivation of PONl according to increased generation of ROS in BD. ${ }^{24}$
To our knowledge, this is the first study which demonstrated that paraoxonase is decreased in patients with Behçet's disease in the active stage. In our study, the BD patients consisted of those who had the complete type of the disease with all the major criteria. Determining PON levels in a larger series of $\mathrm{BD}$ patients also with the incomplete type of disease at various stages could help reveal the underlying pathogenesis. Further studies may also reveal whether this enzyme could be used in the differential diagnosis of the suspected cases, or used as a specific marker for the approaching activation of the disease.

In conclusion, endothelial damage and increased PMN leucocyte activity in the active stage of the disease in BD may result in a pro-oxidation environment which in turn results in decreased antioxidant PON activity and increased lipid peroxidation as evidenced by increased MDA levels.

\section{Authors' affiliations}

S Karakucuk, A O Oner, E Mirza, Department of Ophthalmology, Erciyes University Faculty of Medicine, Kayseri, Turkey

G Baskol, M Ustdal, Department of Biochemistry, Erciyes University Faculty of Medicine, Kayseri, Turkey

M Baskol, Department of Gastroenterology, Erciyes University Faculty of Medicine, Kayseri, Turkey

Correspondence to: S Karakucuk, MD, Erciyes University Faculty of Medicine, Kayseri 38039, Turkey; sarper2002@yahoo.com

Accepted for publication 17 March 2004

\section{REFERENCES}

1 O'Duffy JD. Vasculitis in Behçet's disease. Rheum Dis Clin N Am 1990; 16:423-31.

2 Mochizuki M, Akduman K, Nussenblat RB. Behçet's disease. In: Pepose JS, Holland GN, Wilhelmus KR, eds. Ocular infection and immunity.St Louis, Mosby, 1996:671-72.

3 Niwa Y, Miyake S, Sakane T, et al. Auto-oxidative damage in Behçet's disease-endothelial cell damage following the elevated oxygen radicals generated by stimulated neutrophils. Clin Exp Immunol 1982;49:247-55.

4 Taysi S, Kocer I, Memișogullari R, et al. Serum oxidant/antioxidant status in patients with Behcet's disease. Ann Clin Lab Sci 2002;32:377-82.

5 Dogan $\mathbf{P}$, Soyuer U, Tanrikulu $G$, et al. Changes in serum and polymorphonuclear antioxidant defense system in Behçet's disease. Invest Dermatol 1989;93:297-8.

6 Loeper J, Ement J, Goy J, et al. Lipid peroxidation during human atherosclerosis. IRCS Med Sci 1983;11:1035-43.

7 Orem A, Deger O, Cimsit G, et al. Plasma lipoprotein (a) and its relationship with disease activity in patients with Behçet's disease. Eur J Clin Chem Clin Biochem 1995;33:473-8.

8 Orem A, Deger O, Memis O, et al. Lp(a) lipoprotein levels as a predictor of risk for thrombogenic events in patients with Behçet's disease. Ann Rheum Dis 1995;54:726-9.

9 Mitamura T, Ohmo S, Ariga H, et al. Lipoprotein cholesterol concentrations in patients with Behçet's disease. Clin Chim Acta 1988;175:277-84.

10 Durrington PN, Mackness B, Mackness MI. Paraoxonase and atherosclerosis. Arterioscler Thromb Vasc Biol 2001;21:473-80.

11 Mackness B, Durrington PN, Mackness MI. Human serum paraoxonase. Gen Pharmac 1998;31:329-36.

12 Mackness MIB, Mackness PN, Durrington PW, et al. Paraoxonase: biochemistry, genetics and relationship to plasma lipoproteins. Curr Opin Lipidol 1996;7:69-76.

13 Aviram M, Rosenblat $M$, Bisgaier $C L$, et al. Paraoxonase inhibits high-density lipoprotein oxidation and preserves its functions. A possible peroxidative role for paraoxonase. J Clin Invest 1998;101:1581-90.

14 International Study Group for Behçet's Disease. Criteria for diagnosis of Behçet's disease. Lancet 1990;335:1078-80.

15 Jain SK. Evidence for membrane lipid peroxidation during the in vivo aging of human erythrocytes. Biochem Biophys Acta 1998;937:205-10. 
16 Eckerson HW, Romson J, Wyte $\mathrm{C}$, et al. The human serum paraoxonase polymorphism: Identification of phenotypes by their response to salts. Am J Hum Genet 1983;35:214-27.

17 Henson PM, Johnston RB. Tissue injury and inflammation. J Clin Int 1987:79:669-74.

18 Halliwell B. Free radicals, antioxidants, and human disease: curiosity, cause, or consequence? Lancet 1994;344:721-4.

19 Gutteridge JMC. Free radicals in disease processes: a complication of cause and consequence. Free Radic Res Commun 1993:19:141-58.

20 Halliwell B, Chirico S. Lipid peroxidation: its mechanism, measurement, and significance. Am J Clin Nutr 1993;57(Suppl 1):715S-24S
21 Halliwell B Gutteridge JM. Free radicals in biology and medicine. Oxford: Clarendon Press, 1996: 1-543.

22 Halliwell B. Reactive oxygen species in living system: source, biochemistry, and role in human disease. Am J Med 1991;91(suppl 3C):14S-22S

23 Orem A, Efe H, Deger O, et al. Relationship between lipid peroxidation and disease activity in patients with Behçet's disease. J Dermatol Sci 1997;16:11-16.

24 Aviram M, Rosenblat M, Billecke S, et al. Human serum paraoxonase (PON1) is inactivated by oxidized low density lipoprotein and preserved by antioxidants. Free Radic Biol Med 1999;26:892-904. 